\title{
Nucleation behaviour and microstructure of single Al- Si12 powder particles rapidly solidified in a fast scanning calorimeter
}

\author{
Bin Yang ${ }^{1,2, *}$ (1), Qin Peng ${ }^{2}$, Benjamin Milkereit ${ }^{1,2}$, Armin Springer $^{3}$, Dongmei Liu ${ }^{4}$, \\ Markus Rettenmayr ${ }^{4}$, Christoph Schick ${ }^{1,5,6}$, and Olaf Keßler ${ }^{1,2}$ \\ ${ }^{1}$ Department Life, Light and Matter, Competence Centre ${ }^{\circ}$ CALOR, University of Rostock, Albert-Einstein-Str. 25, 18059 Rostock, \\ Germany \\ ${ }^{2}$ Chair of Materials Science, University of Rostock, Justus-von-Liebig-Weg 2, 18059 Rostock, Germany \\ ${ }^{3}$ Medical Biology and Electron Microscopy Centre, University Medicine Rostock, Strempelstr. 14, 18057 Rostock, Germany \\ ${ }^{4}$ Otto Schott Institute of Materials Research, Friedrich-Schiller-University Jena, Löbdergraben 32, 07743 Jena, Germany \\ ${ }^{5}$ Institute of Physics, University of Rostock, Albert-Einstein-Str. 23-24, 18059 Rostock, Germany \\ ${ }^{6}$ Butlerov Institute of Chemistry, Kazan Federal University, 18 Kremlyovskaya Street, Kazan, Russia 420008
}

Received: 22 January 2021

Accepted: 8 April 2021

Published online:

19 April 2021

(C) The Author(s) 2021

\begin{abstract}
The understanding of rapid solidification behaviour, e.g. the undercooling versus growth velocity relationship, is crucial for tailoring microstructures and properties in metal alloys. In most rapid solidification processes, such as additive manufacturing (AM), in situ investigation of rapid solidification behaviour is missing because of the lack of accurate measurement of the cooling rate and nucleation undercooling. In the present study, rapid solidification of single micro-sized Al-Si12 (mass\%) particles of various diameters has been investigated via differential fast scanning calorimetry employing controllable cooling rates from 100 to $90,000 \mathrm{~K} \mathrm{~s}^{-1}$ relevant for AM. Based on nucleation undercooling and on microstructure analysis of rapidly solidified single powder particles under controlled cooling rates, two different heterogeneous nucleation mechanisms of the primary $\alpha-\mathrm{Al}$ phase are proposed. Surface heterogeneous nucleation dominates for particles with diameter smaller than $23 \mu \mathrm{m}$. For particles with diameter larger than $23 \mu \mathrm{m}$, the nucleation of the primary $\alpha$-Al phase changes from surface to bulk heterogeneous nucleation with increasing cooling rate. The results indicate that at large undercoolings $(>95 \mathrm{~K})$ and high cooling rates $\left(>10,000 \mathrm{~K} \mathrm{~s}^{-1}\right)$, rapid solidification of single particle can yield a microstructure similar to that formed in AM. The present work not only proposes new insight into rapid solidification processes, but also provides a
\end{abstract}

Handling Editor: Catalin Croitoru.

Address correspondence to E-mail: bin.yang@uni-rostock.de 
theoretical foundation for further understanding of microstructures and properties in additively manufactured materials.

\section{Introduction}

Rapid solidification of metal particles is an important process in many production chains of metal components. Recently, rapid solidification has attracted further interest as it is intrinsically linked to the evolving field of additive manufacturing (AM). AM of metals holds great potential for improving materials' efficiency, reducing life-cycle impacts, enabling greater engineering functionality and allowing fast reaction to customers' demands [1, 2]. Al-based alloys such as $\mathrm{Al}-\mathrm{Si}$ alloys are important engineering materials in general and are frequently used in AM. Attention has therefore been given to understand the rapid solidification processes of micro-sized metal particles in AM processes and their influence on the developing microstructures [3-7]. Undercooling and nucleation influence practically relevant microstructural features such as grain size and hot cracking susceptibility. The solidification cooling rates in AM processes range from about $100 \mathrm{~K} \mathrm{~s}^{-1}$ up to $10^{6} \mathrm{~K} \mathrm{~s}^{-1}$ [7-11]. For example, the cooling rate of Al-Si12 (mass\%) in laser powder bed fusion (LPBF, sometimes also called laser beam melting or selective laser melting, LBM/SLM) was estimated (based on simulations) to be above $10^{3} \mathrm{~K} \mathrm{~s}^{-1}$ for most parts of the melt pool [9]. Besides, by using other rapid solidification techniques, similar high cooling rates can be achieved. Numerous studies have been reported on the rapid solidification of $\mathrm{Al}-\mathrm{Si}$ alloys by melt spinning, gas atomisation, laser melting, spray forming, etc. [12-15], especially for the nucleation undercooling in Al-Si alloy particles [13, 16-18]. However, the in situ investigation of the rapid solidification behaviour of powder particles under such conditions is not straight forward. Hence, so far ex situ investigations and numerical simulation are commonly applied to study the transient, non-equilibrium states during rapid solidification under such extreme conditions far away from thermodynamic equilibrium $[3,4,7,13]$. Unfortunately, the quality of those estimates is hard to evaluate since particularly the occurrence and lifetime of transient non-equilibrium states are not easy to verify experimentally. Hence, the predictions of the solidification mechanisms have been supported by only a few quantitative studies [19-22]. Thus, in situ investigations of rapid solidification revealing the solidification temperature intervals, and its nucleation mechanisms (e.g. nucleation kinetics) are lacking. However, for a proper description of rapid solidification, these results are crucial and fundamental for proper parameter selection in additive manufacturing. A better understanding of rapid solidification at such high cooling rates requires accurate measurements of the cooling rate and solidification temperature intervals and an accurate description of its mechanisms.

In the present work, a non-adiabatic differential fast scanning calorimeter (DFSC) [23] with a wide range of controllable cooling rates ranging from 100 to $90,000 \mathrm{~K} \mathrm{~s}^{-1}$, covering the cooling rate in $\mathrm{AM}$, was utilised for in situ analysis of rapid solidification. This thermal analysis device provides the opportunity to investigate the fundamental issues related to rapid solidification of single micro-sized, nearspherical particles, such as the solidification temperature intervals and nucleation kinetics. Particle size is a crucial factor in the nucleation kinetics, especially for determining nucleation undercooling [17, 24, 25]. Therefore, micro-sized Al-Si12 (mass\%) particles with diameters from 6 to $34 \mu \mathrm{m}$ were used. By combining DFSC analysis and microstructure analysis, the rapid solidification behaviour of single Al-Si12 particles, specifically the nucleation mechanism of the primary $\alpha$-Al phase, is discussed. A modified classical heterogeneous nucleation theory, which assumes surface nucleation in a spherical cavity and/or bulk nucleation on a convex spherical interface, is developed.

\section{Experimental procedure}

Gas-atomised Al-Si12 (mass\%) powders supplied by Nanoval GmbH \& Co. KG (Germany) were used in the present work. The composition of the as-received powders was analysed by X-ray fluorescence spectroscopy (XRF) (see Table 1). The composition is close to the nominal composition. The microstructure of 
the cross section of as-received Al-Si12 powders was characterised using a scanning electron microscope (SEM) (Zeiss Merlin VP Compact, Germany), as shown in Fig. 1. The microstructure is composed of $\alpha$ $\mathrm{Al}$ dendrites and $(\alpha-\mathrm{Al}+\mathrm{Si})$ eutectics, where the grey and bright areas are $\mathrm{Al}$ and $\mathrm{Si}$, respectively.

DFSC based on thin film chip sensors [23] was used for the in situ measurements of the melting and solidification temperatures. The sensor, UFH1 (Mettler Toledo, Switzerland), consists of an amorphous silicon-nitride membrane with film thermopiles and resistive film heaters placed at the centre of the membrane, as shown in Fig. 2. Particles of nearspherical shape with diameters ranging from 6 to $28 \mu \mathrm{m}$ were chosen for DFSC measurements. The particle sizes were characterised by optical microscopy (Olympus BX41, Japan) before and after the measurements. A single micro-sized particle was deposited in the centre of the measurement area (see Fig. 2) by a thin copper wire under a stereomicroscope (Olympus SZX16, Japan). To improve the heat contact between the sample and membrane, a tiny amount of silicone oil was used. The boiling temperature of silicone oil is ca. $250{ }^{\circ} \mathrm{C}$ at low heating rates. However, due to the high heating rates investigated and thus short times at high temperatures, the silicone oil was expected to be stable up to high temperatures. After the first melting and solidification cycle, an improved thermal contact between the sample and membrane was established due to slight flattening of the particle.

To investigate the rapid solidification of Al-Si12 particles by DFSC, the single particle was heated at $5000 \mathrm{~K} \mathrm{~s}^{-1}$ from 37 to $707{ }^{\circ} \mathrm{C}$ and held for $0.01 \mathrm{~s}$ under argon atmosphere at a constant pressure of $100 \mathrm{kPa}$. As the liquidus temperature of Al-Si12 is near the eutectic temperature of the Al-Si-system $577^{\circ} \mathrm{C}$ [27], this maximum heating temperature ensures a certain overheating even at high heating rates. Afterwards, the single particle was cooled to $37^{\circ} \mathrm{C}$ at cooling rates from 100 to $90,000 \mathrm{~K} \mathrm{~s}^{-1}$. The temperature dependence of the accessible scanning

Table 1 Mass fractions of alloying elements in the as-received Al-Si12 powders

\begin{tabular}{llllll}
\hline Alloy & $\mathrm{Al}$ & $\mathrm{Si}$ & $\mathrm{Fe}$ & $\mathrm{Cr}$ & $\mathrm{V}$ \\
\hline Al-Si12 & ca. $88 \%$ & $11.80 \%$ & $0.16 \%$ & $0.02 \%$ & $0.01 \%$ \\
\hline
\end{tabular}

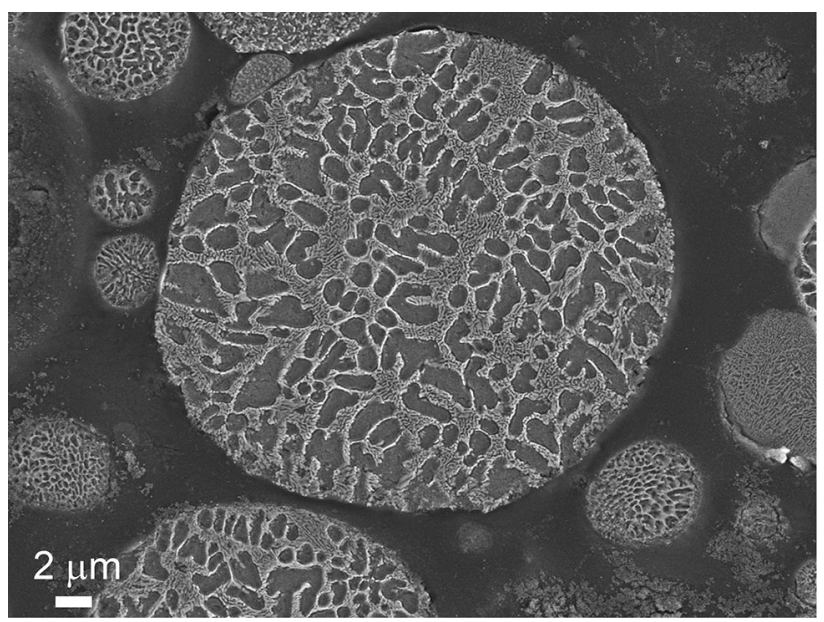

Figure 1 SEM secondary electron images of the cross section of an as-atomised Al-Si12 particle, etched with Weck's reagent [26].

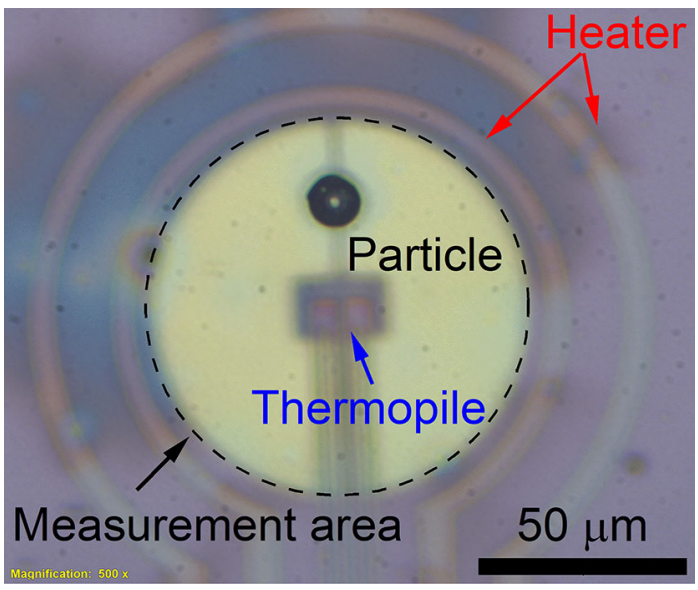

Figure 2 Single Al-Si12 powder particle of $13 \mu \mathrm{m}$ in diameter on a UFH1 DFSC sensor.

rate of a particle of $7 \mu \mathrm{m}$ in diameter (from 100 to $90,000 \mathrm{~K} \mathrm{~s}^{-1}$ ) is demonstrated in Fig. 3a, indicating that cooling rates as high as $90,000 \mathrm{~K} \mathrm{~s}^{-1}$ are controllable in the aimed temperature range of 600 $350{ }^{\circ} \mathrm{C}$. For improved reproducibility, identical conditions, i.e. heating rate, overheating and time above liquidus temperature of the single particle before subsequent cooling, were applied. For each cooling rate, ca. 100 repeated cooling-heating cycles were performed on each single particle to appropriately account for the stochastic nature of the nucleation process. A representative temperature-time profile (with a heating and cooling rate of $5000 \mathrm{~K} \mathrm{~s}^{-1}$ ) is shown in Fig. 3b. During this heating-cooling process, the heat flow was recorded as a function of time. During the heating-cooling cycle, the Al-Si12 particle 


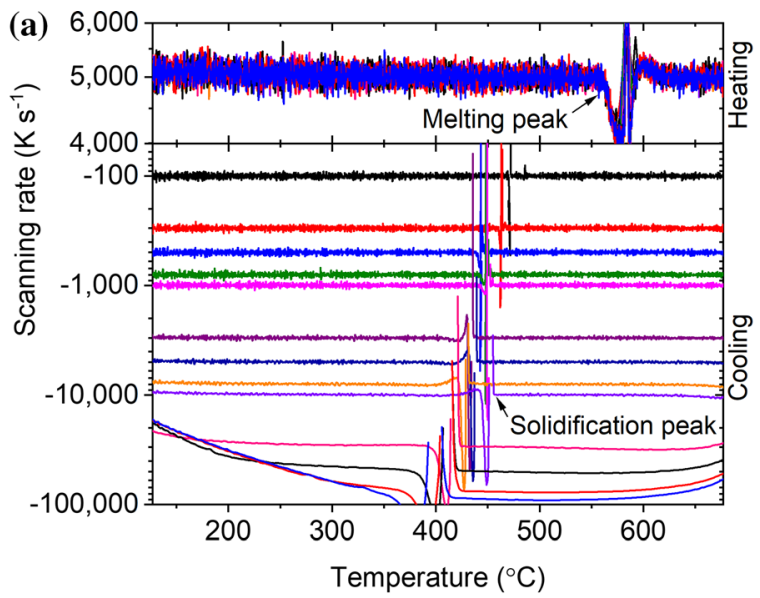

(b)

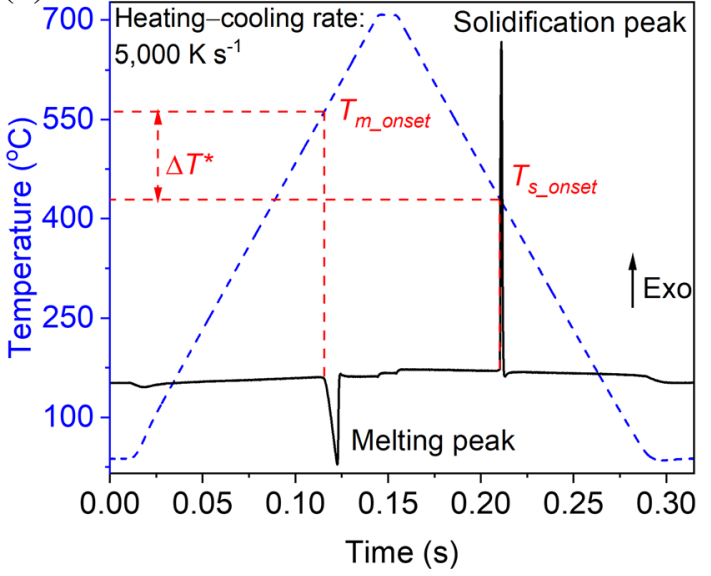

Figure 3 a Scanning rates of a single Al-Si12 particle $(7 \mu \mathrm{m}$ in diameter) by DFSC indicating that cooling rates as high as $90,000 \mathrm{~K} \mathrm{~s}^{-1}$ are controllable in the temperature range of $600{ }^{\circ} \mathrm{C}-$ $350^{\circ} \mathrm{C}$. $\mathbf{b}$ Typical DFSC measurement curve of the melting and solidification processes of a single Al-Si12 particle. The dashed curve is the temperature-time profile, and the solid curve is the

underwent melting and solidification. The melting onset temperature, $T_{m \_o n s e t}$ and the solidification onset temperature, $T_{s_{-} \text {onset, }}$ were determined [28]. The temperature calibration and correction (accounting for a static temperature offset and a dynamic temperature offset due to thermal lag) for each particle were performed by the eutectic temperature of AlSi12 alloy upon heating (for details see "Appendix"). According to the Al-Si phase diagram [27], the liquidus temperature, $T_{1}$, is approximated to the eutectic temperature, $T_{\mathrm{e}}$, for Al-Si12 particles. Therefore, the nucleation undercooling, $\Delta T$, can be calculated by

$\Delta T=T_{1}-T_{\mathrm{n}}=T_{m \_ \text {onset }}^{\text {correct }}-T_{s \_ \text {onset }}^{\text {correct }}$

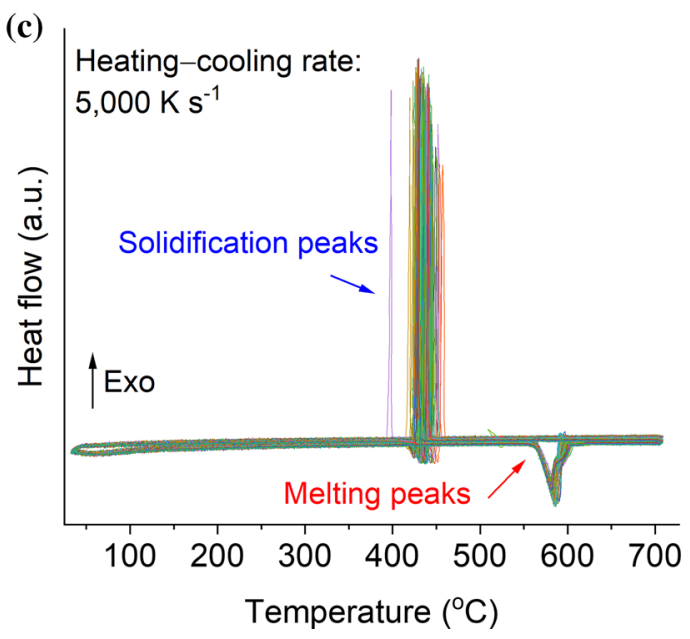

heat flow curve. The melting onset temperature, $\mathrm{T}_{m_{-} \text {onset, }}$ the solidification onset temperature, $\mathrm{T}_{s_{-} \text {onset, }}$, and the uncorrected undercooling, $\Delta T^{*}$, are indicated in the figure. c 100 measured curves of a single Al-Si12 particle $(14 \mu \mathrm{m}$ in diameter $)$ at $5000 \mathrm{~K} \mathrm{~s}^{-1}$ heating/cooling rate.

where $T_{\mathrm{n}}, T_{m \text { onset }}^{\text {correct }}$ and $T_{s \text { onset }}^{\text {correct }}$ are the nucleation temperature, the corrected melting and solidification onset temperatures for each scanning rate, respectively. It should be noted that the melting onset temperature did not change in the course of the repeated experiments, as shown in Fig. 3c. This indicates not only the repeatability of the DFSC analysis but also the stable shape and composition of the single Al-Si12 particle during all the experiment cycles. Thus, the influence of the particle shape on the nucleation undercooling can be neglected. The scatter of the onset temperatures of the solidification peaks even with the same cooling rate in Fig. $3 c$ comes from the stochastic nature of the nucleation process. 
Finally, the microstructures of single rapidly solidified particles with controlled cooling rates by DFSC were investigated. According to the analysis of the DFSC results (for details see next section "Undercooling dependence on cooling rate and particle size"), two sets of particles with certain sizes were chosen, i.e. ca. $20 \mu \mathrm{m}$ and ca. $32 \mu \mathrm{m}$ in diameter. Four cooling rates were chosen, namely $100 \mathrm{~K} \mathrm{~s}^{-1}$, $500 \mathrm{~K} \mathrm{~s}^{-1}, 5000 \mathrm{~K} \mathrm{~s}^{-1}$ and $50,000 \mathrm{~K} \mathrm{~s}^{-1}$, respectively. It should be mentioned that one specific particle was chosen for each selected cooling rate and size for microstructure characterisation. After solidification by DFSC at a controlled cooling rate, resulting in a known undercooling, the single particle was transferred from the DFSC sensor and placed into a coneshaped bore in an epoxy block with a thin copper wire under a stereomicroscope. Then, the bore was carefully filled with epoxy resin, avoiding movement of the particle. After hardening the epoxy resin in the bore, the epoxy block was ground and polished carefully until obtaining the particle's cross section. Then the specimen was etched with Weck's reagent $\left(100 \mathrm{~mL}\right.$ water, $4 \mathrm{~g} \mathrm{KMnO}_{4}$ and $\left.1 \mathrm{~g} \mathrm{NaOH}\right)$ for $4 \mathrm{~s}$. Details of the specimen preparation for microstructure characterisation of one single microsized particle can be found in [29]. The cross-sectional microstructure of the particle was characterised by SEM. A linear intercept method [30] was applied to measure the $\alpha-\mathrm{Al}$ dendrite arm spacing (DAS). Therefore, about 18 lines in different directions with a total length of about $250 \mu \mathrm{m}$ were placed on the cross section of each single particle.

\section{Results and discussion}

\section{Undercooling dependence on cooling rate and particle size}

Solidification of metals requires a certain degree of nucleation undercooling. By controlling undercooling, different scenarios of crystal nucleation, resulting in a variety of solidification structures with superior material properties, can be obtained [31, 32]. During rapid solidification by DFSC, the solidification onset temperature (e.g. shown in Fig. 3c) is lower than $500{ }^{\circ} \mathrm{C}$. According to the calculated Al-rich boundary of the coupled zone in laser-treated Al-Si alloys [33], during rapid solidification of an Al-Si12 alloy, the primary $\alpha$-Al phase solidifies first from the melt, followed by the formation of $(\alpha-\mathrm{Al}+\mathrm{Si})$ eutectic due to the coupled zone $[33,34]$. Therefore, the solidification onset upon cooling corresponds to the nucleation of the primary $\alpha$-Al phase, and the nucleation undercooling of the primary $\alpha$-Al phase can be calculated by Eq. (1). It should be noted that the undercooling of the second eutectic phase cannot be evaluated because of the overlapping solidification peaks, as shown in Fig. 3c. The dependence of the nucleation undercooling on the cooling rate of an AlSi12 particle of $7 \mu \mathrm{m}$ in diameter is shown in Fig. 4a. For a sound statistical basis, the heating-cooling process was repeated 100 times for each cooling rate. As expected, due to the stochastic nature of nucleation, nucleation occurs in a temperature range where the mean value of the undercooling
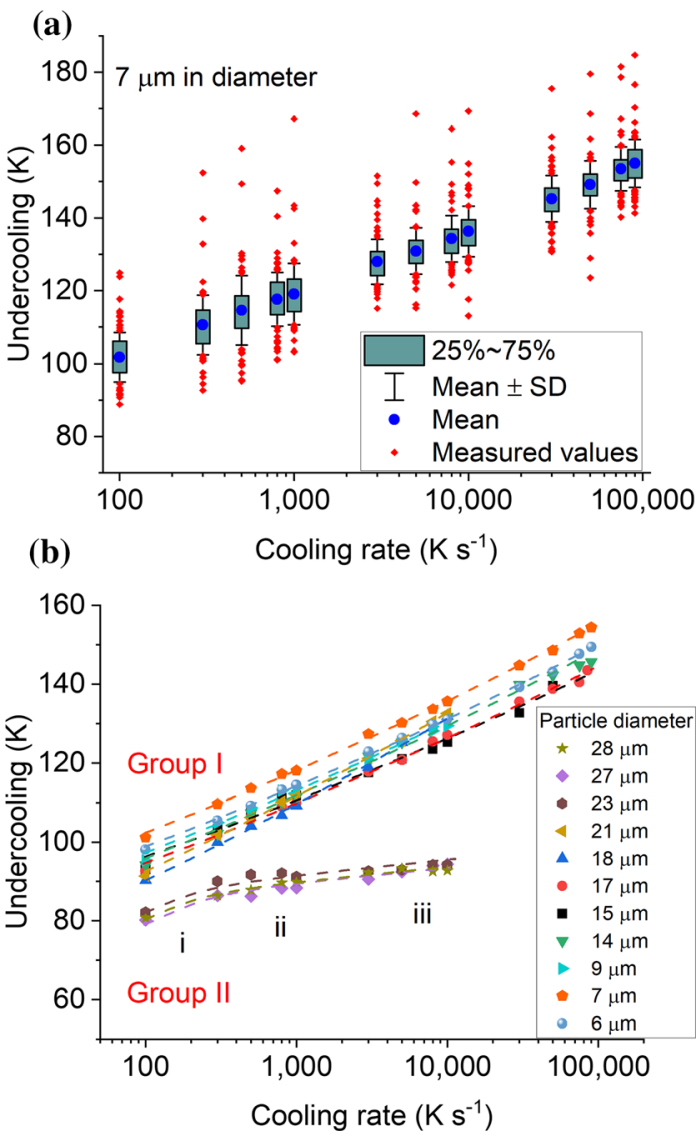

Figure 4 a Nucleation undercooling of an Al-Si12 particle of $7 \mu \mathrm{m}$ in diameter measured at cooling rates from 100 to $90,000 \mathrm{~K} \mathrm{~s}^{-1}$ (box plot). For each cooling rate, 100 heatingcooling cycles were performed. The mean values of undercooling are indicated by blue circles. The error bars show the standard deviation (SD). b Undercooling of single Al-Si12 particles with different sizes for a series of cooling rates: dashed curves-fitted curves (for details see text). 
corresponding to a specific cooling rate is indicated by the blue circle symbol. The mean nucleation undercooling increases with increasing cooling rate. The variance of undercooling because of the stochastic nature of nucleation is about $40 \mathrm{~K}$ for each cooling rate between 100 and $90,000 \mathrm{~K} \mathrm{~s}^{-1}$.

The dependence of the mean nucleation undercooling of single Al-Si12 particles with different diameters (6 to $28 \mu \mathrm{m}$ ) on the cooling rate from 100 to $90,000 \mathrm{~K} \mathrm{~s}^{-1}$ is illustrated in Fig. 4b. The undercooling is in a similar range as the estimated undercooling of atomised Al-Si eutectic alloy particle [13]. For particles larger than $23 \mu \mathrm{m}$ in diameter, no sufficient data set can be obtained up to the cooling rate of $10,000 \mathrm{~K} \mathrm{~s}^{-1}$. This is because of the serious dynamic temperature offset due to the thermal lag at higher cooling rates, resulting from high heat capacities of large particles. This cooling rate of $10,000 \mathrm{~K} \mathrm{~s}^{-1}$ is still relevant for L-PBF processes with typical cooling rates above $1000 \mathrm{~K} \mathrm{~s}^{-1}$ [9]. Even though measured undercooling is not reliable for particles larger than $23 \mu \mathrm{m}$, they can be cooled at rates up to $50,000 \mathrm{~K} \mathrm{~s}^{-1}$ and their microstructure becomes accessible. For smaller particles with diameters from 6 to $21 \mu \mathrm{m}$, cooling rates of up to $90,000 \mathrm{~K} \mathrm{~s}^{-1}$ can be achieved. For these smaller particles (Group I) a linear increase in nucleation undercooling with increasing cooling rate (logarithmic scale) was observed. Further, undercooling decreases with increasing particle size. This is similar to the observation on pure Sn particles [24], pure Al particles [17], Al-Si alloy particles [18] and $\mathrm{Al}-\mathrm{Cu}$ alloy particles [25]. However, for particles with diameters larger than $23 \mu \mathrm{m}$ (Group II), a transition of the undercooling dependence was observed, marked as regions i, ii and iii in Fig. $4 \mathrm{~b}$. The change in slope indicates a transition of the nucleation mechanism at a certain cooling rate, which is also dependent on the particle size. The two groups of undercooling behaviour are termed as Group I and Group II.

For rationalising the nucleation behaviour dependent on the cooling rate and particle size, a theoretical interpretation based on the classical nucleation theory (CNT) is proposed. For continuous cooling, the nucleation rate becomes time, $t$, respectively, temperature, $T$, dependent. Taking into consideration both heterogeneous mechanisms of bulk and surface nucleation, the total number of nuclei, $N$, of a single Al-Si12 particle at a certain nucleation undercooling
$\Delta T$ (Eq. 1), at a constant cooling rate, $\beta_{c}$, is given by [19]

$$
\begin{aligned}
N & =\int_{0}^{t}\left(J_{V} V+J_{S} S\right) \mathrm{d} t=\frac{1}{\beta_{c}} \int_{T_{S_{-} \text {onset }}}^{T_{m}{ }_{\text {onset }}}\left(J_{V} V+J_{S} S\right) \mathrm{d} T \\
& =\frac{1}{\beta_{c}} \int_{0}^{\Delta T}\left(J_{V} V+J_{S} S\right) \mathrm{d} \Delta T
\end{aligned}
$$

where $J_{V}$ and $J_{S}$ are the bulk and surface nucleation rates, respectively; and $V\left(=\pi \mathrm{d}^{3} / 6\right.$, where $\mathrm{d}$ is the particle diameter) and $S\left(=\pi \mathrm{d}^{2}\right)$ are the volume and surface area of a particle, respectively. It is assumed that at first only one nucleus forms at the temperature $T_{s_{-} \text {onset }}$, i.e. $N=1$. Thus, the nucleation undercooling $\Delta T$ (and the temperature $T_{S_{-} \text {onset }}$ ), as well as the time when the first supercritical nucleus forms, can be determined by Eq. (2).

Based on the spherical cap model of CNT, the expressions for the heterogeneous surface and bulk nucleation rates of a single particle during a rapid cooling process are derived in $[35,36]$ as

$J_{S}=n_{S} \frac{\boldsymbol{D}_{1}}{\boldsymbol{a}_{0}} \sqrt{\frac{\boldsymbol{\sigma}_{l s}}{\boldsymbol{k}\left(T_{m \_ \text {onset }}-\Delta T\right)}} \exp \left(-\frac{\Delta G^{*} f_{S}}{k\left(T_{m \_ \text {onset }}-\Delta T\right)}\right)$

and

$J_{V}=n_{V} \frac{\boldsymbol{D}_{1}}{\boldsymbol{a}_{0}} \sqrt{\frac{\boldsymbol{\sigma}_{\boldsymbol{l s}}}{\boldsymbol{k}\left(T_{m \_ \text {onset }}-\Delta T\right)}} \exp \left(-\frac{\Delta G^{*} f_{V}}{k\left(T_{m \_ \text {onset }}-\Delta T\right)}\right)$

with

$\Delta G^{*}=\frac{16 \pi \sigma_{l s}^{3}}{3 \Delta G_{V}^{2}}$

where $n_{S}$ and $n_{V}$ are the numbers of potential surface and bulk heterogeneous nucleation sites per unit surface area and volume (densities of surface and bulk heterogeneous nucleation sites), respectively, $D_{1}$ is the liquid diffusivity, $a_{0}$ is the atomic spacing, $\sigma_{l s}$ is the solid-liquid interfacial energy, $k$ is the Boltzmann constant, $\Delta G_{V}$ is the free energy difference between the melt and the solidified phase, and $f_{S}$ and $f_{V}$ are the shape factors for surface and bulk heterogeneous nucleation, which describe the potency of the heterogeneous nuclei. In the absence of specific heat capacity data, especially in the undercooled region, $\Delta G_{V}$ is estimated from the melting enthalpy $\Delta H_{V}$ and 
the melting temperature $T_{m \_ \text {onset. }} \Delta G_{V}$ can be approximated by the expression of Thompson and Spaepen [37]

$\Delta G_{V}=\frac{\Delta \boldsymbol{H}_{V}}{T_{m \_ \text {onset }}} \frac{2\left(T_{m \_ \text {onset }}-\Delta T\right)}{2 T_{m \_ \text {onset }}-\Delta T}$

Assuming that a surface nucleus for $\alpha$ - $\mathrm{Al}$ forms in a spherical cavity at the surface of the particle (surface nucleation on the $\mathrm{Al}_{2} \mathrm{O}_{3}$ oxide layer) or on a convex spherical interface inside the particle (bulk nucleation on impurities), as illustrated in Fig. 5a, the shape factors, $f_{S}$ and $f_{V}$, according to [38], can be expressed by

$$
\begin{aligned}
f_{S}= & \frac{1}{4 \rho_{S}^{3}}\left(-1+2 \rho_{S}+\sqrt{1+\rho_{S}^{2}+2 \rho_{S} \cos \theta_{S}}\right) \\
& \left(1+\rho_{S}-\sqrt{1+\rho_{S}^{2}+2 \rho_{S} \cos \theta_{S}}\right)^{2}
\end{aligned}
$$

and

$$
\begin{aligned}
f_{V}= & \frac{1}{4 \rho_{V}^{3}}\left(1+2 \rho_{V}-\sqrt{1+\rho_{V}^{2}-2 \rho_{V} \cos \theta_{V}}\right) \\
& \left(-1+\rho_{V}+\sqrt{1+\rho_{V}^{2}-2 \rho_{V} \cos \theta_{V}}\right)^{2}
\end{aligned}
$$

with

$\rho_{S, V}=\frac{r^{*}}{R_{S, V}}$

where $\theta_{S}$ and $\theta_{V}$ are the contact angles between the undercooled melt and the heterogeneous nucleus for the surface and bulk heterogeneous nucleation, respectively; $R_{S}$ and $R_{V}$ are the radii of the spherical cavity and the convex spherical interface, respectively; and $r^{*}$ is the critical radius of a nucleus based on CNT, which is expressed by

$r^{*}=\frac{2 \sigma_{l s}}{\Delta G_{V}}$

To complete the description of this model, the density of bulk heterogeneous nucleation sites can be taken to follow the form [39]

$n_{V}=n_{V}^{0} \exp (b \Delta T)$

where $n_{V}^{0}$ is the base level of nucleation sites $\left(=10^{13} \mathrm{~m}^{-3}\right)$, and $b$ is a positive constant $(=0.059)$ [39]. For all the particles in this study, $n_{V}$ is in the range of $10^{14}-10^{16} \mathrm{~m}^{-3}$. During the DFSC measurements, an inherent $\mathrm{Al}_{2} \mathrm{O}_{3}$ layer always exists. Therefore, assuming all the $\mathrm{Al}_{2} \mathrm{O}_{3}$ on the surface of the $\mathrm{Al}-$
Si12 particle are possible nucleation sites of surface heterogeneous nucleation, the density of surface heterogeneous nucleation sites can be calculated by

$n_{S}=\frac{N_{A} h}{V_{\mathrm{m}}}$

where $N_{A}$ is Avogadro constant, $h$ is the thickness of $\mathrm{Al}_{2} \mathrm{O}_{3}$ layer $(=1 \mathrm{~nm})$ [40], and $V_{\mathrm{m}}$ is the molar volume of $\mathrm{Al}_{2} \mathrm{O}_{3}\left(=25.7 \times 10^{-6} \mathrm{~m}^{3} \mathrm{~mol}^{-1}\right)$ [40]. Thus, $n_{S}$ equals $2.343 \times 10^{19} \mathrm{~m}^{-2}$.

Based on this model, the change of the nucleation activity of a certain heterogeneity for different undercooling can be estimated. For Al-Si12 particles, $T_{m_{-} \text {onset }}=577.5^{\circ} \mathrm{C}, \quad \sigma_{l s}=0.169 \mathrm{~J} \mathrm{~m}^{-2}(\mathrm{Al}$ in $\mathrm{Al}-\mathrm{Si}$ system) [41], $\Delta H_{V}=12.4 \times 10^{8} \mathrm{~J} \mathrm{~m}^{-3}$ (measured by DSC for as-atomised Al-Si12 powders), $D_{l-}$ $=5 \times 10^{-9} \mathrm{~m}^{2} \mathrm{~s}^{-1}$ [42], and $a_{0}=2.6 \times 10^{-10} \mathrm{~m}$ (for pure $\mathrm{Al}$ ) [43]. Employing these parameters, the data were fitted for cooling rates ranging from 100 to $90,000 \mathrm{~K} \mathrm{~s}^{-1}$. Here $\theta_{S}, \theta_{V}, R_{S}$ and $R_{V}$ are fitting parameters. Boundary conditions were set for each parameter: $20^{\circ}<\theta_{S, V} \leq 180^{\circ}$ (for the spherical cap model the contact angle is larger than $20^{\circ}$ [44]); $0.1 \mathrm{~nm}<R_{S, V}<10 \mathrm{~nm}$. Nonlinear least squares curve fitting (Levenberg-Marquardt algorithm) was utilised. The fitted curves are indicated by dashed lines in Fig. $4 \mathrm{~b}$ and the results as well as the coefficients of determination, $R^{2}$, are displayed in Table 2 . No value given in Table 2 means that this part of the model, i.e. bulk nucleation, does not fit the data. For particles with larger size $(>23 \mu \mathrm{m}$ in diameter, Group II), two nucleation mechanisms are suggested, while for smaller size particles $(<23 \mu \mathrm{m}$ in diameter, Group I) only surface heterogeneous nucleation dominates. For each particle, the contact angles of surface and bulk nucleation are the same for different cooling rates: approximately $103^{\circ}-114^{\circ}$ and $34^{\circ}$, respectively. The contact angle of surface nucleation determined is consistent with the contact angle between $\mathrm{Al}$ and $\mathrm{Al}_{2} \mathrm{O}_{3}$ in [45]. This supports the assumption of surface nucleation occurring on the $\mathrm{Al}_{2} \mathrm{O}_{3}$ oxide layer. For bulk nucleation, the nuclei probably form on impurities inside the particle.

The dependence of the nucleation undercooling on the cooling rate for particles of $7 \mu \mathrm{m}, 17 \mu \mathrm{m}$ and $27 \mu \mathrm{m}$ in diameter is shown in Fig. 5b. Undercooling for the particle of $27 \mu \mathrm{m}$ in diameter is determined by two different nucleation mechanisms. Similar behaviour was observed for pure Sn particles solidified at 
Figure 5 a Schematic of the nucleation mechanisms of rapidly solidified $\mathrm{Al}-\mathrm{Si}$ particles. $\mathbf{b}$ Dependence of undercooling on cooling rate for studied particles of $7 \mu \mathrm{m}$, $17 \mu \mathrm{m}$ and $27 \mu \mathrm{m}$ in diameter: solid curves - surface and bulk nucleation, dashed curvessurface nucleation, short dashed curves - bulk nucleation. c Dependence of the surface and bulk nucleation rates on the undercooling for the studied particle of $27 \mu \mathrm{m}$ in diameter: solid curvesurface nucleation, dashed curve-bulk nucleation. (a)
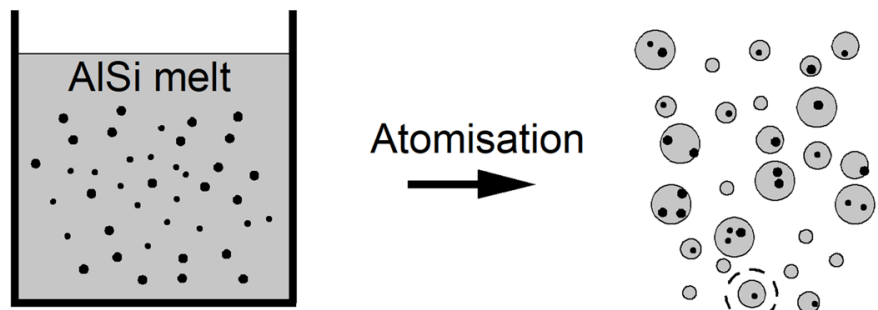

(-) 0

- íio
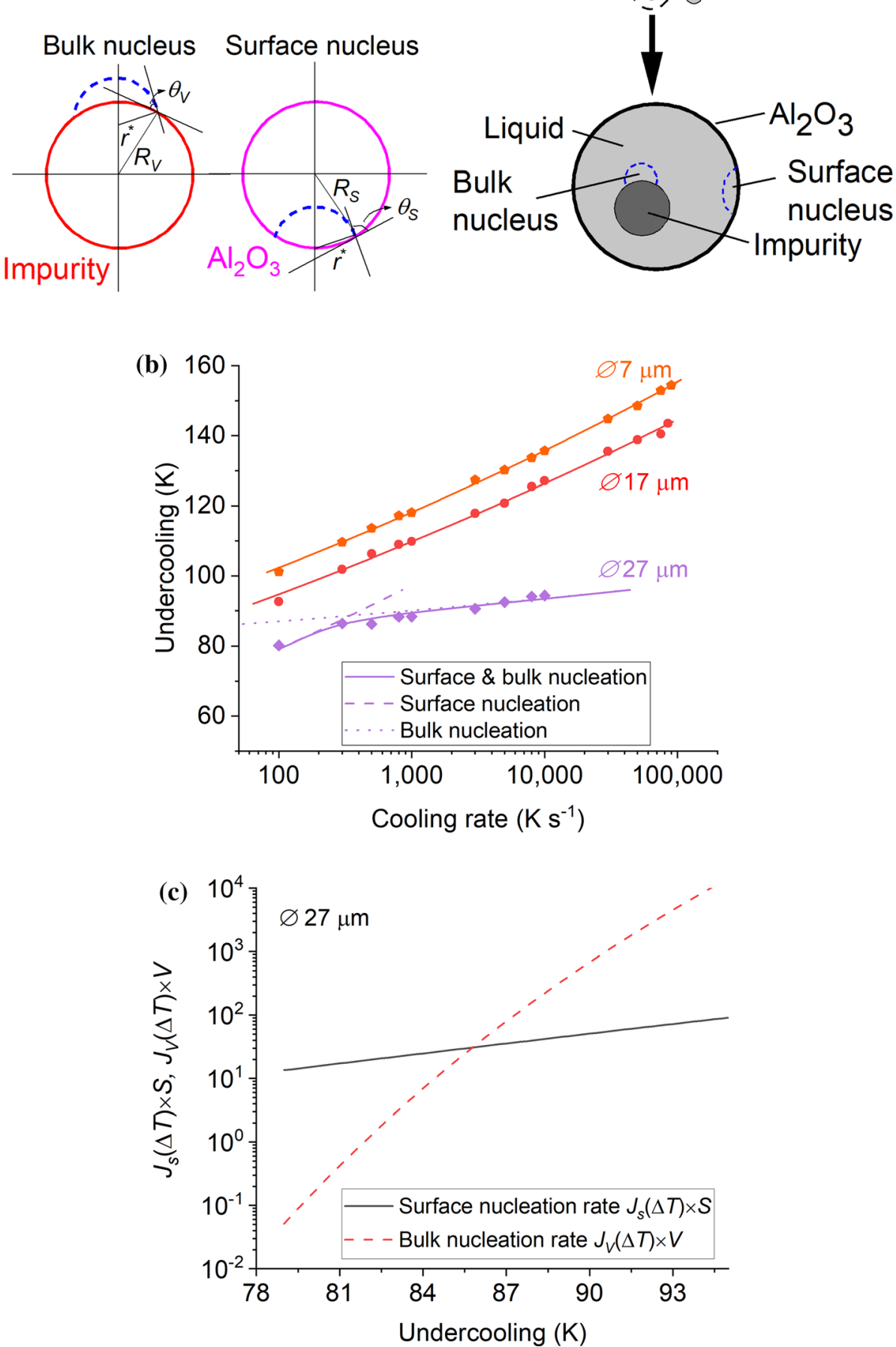

cooling rates from 20 to $40,000 \mathrm{~K} \mathrm{~s}^{-1}$ [24, 46]. Based on the theoretical approach mentioned above, surface heterogeneous nucleation is dominant at low cooling rates, and is replaced by bulk heterogeneous 
Table 2 Parameters obtained by fitting the model to different particle sizes

\begin{tabular}{llllll}
\hline$d(\mu \mathrm{m})$ & $\theta_{S}\left({ }^{\circ}\right)$ & $R_{S}(\mathrm{~nm})$ & $\theta_{V}\left({ }^{\circ}\right)$ & $R_{V}(\mathrm{~nm})$ & $R^{2}$ \\
\hline 6 & 103.10 & 0.96 & & & 0.999 \\
7 & 104.66 & 0.95 & & & 1.000 \\
9 & 104.97 & 0.94 & & & 0.996 \\
14 & 106.56 & 0.92 & & & 0.996 \\
15 & 103.09 & 0.98 & & & 0.992 \\
17 & 105.16 & 0.94 & & & 0.998 \\
18 & 113.60 & 0.81 & & & 0.999 \\
21 & 113.23 & 0.82 & & & 0.999 \\
23 & 112.31 & 0.82 & 34.28 & 7.45 & 0.954 \\
27 & 112.26 & 0.82 & 33.90 & 7.45 & 0.975 \\
28 & 112.45 & 0.82 & 34.02 & 7.45 & 0.990 \\
\hline
\end{tabular}

nucleation at high cooling rates. In between, there is a transition region, e.g. from 300 to $1000 \mathrm{~K} \mathrm{~s}^{-1}$ for the particle of $27 \mu \mathrm{m}$ in diameter, as shown in Fig. 5b. In order to understand this behaviour, the dependence of the heterogeneous surface and bulk nucleation rates on the undercooling is calculated by Eqs. ( 3 and 4) with the fitted parameters listed in Table 2. The results are shown in Fig. 5c. At low undercoolings/cooling rates, the bulk heterogeneous nucleation rate is lower than the surface heterogeneous nucleation rate, and vice versa. Therefore, surface heterogeneous nucleation is preferred at low cooling rates, whereas bulk heterogeneous nucleation is preferred at high cooling rates. For the particles of $7 \mu \mathrm{m}$ and $17 \mu \mathrm{m}$ in diameter, surface nucleation dominates in the whole investigated cooling rate range. With decreasing particle size, fewer impurities are expected inside the particle [35, 47], i.e. fewer bulk heterogeneous nucleation sites, as illustrated in Fig. 5a. For example, the number of bulk nucleation sites is even less than 1 inside the particle of $6 \mu \mathrm{m}$ in diameter, calculated by Eq. (11). Therefore, surface heterogeneous nucleation dominates for small particles.

\section{Microstructure of single rapidly solidified particles at controlled cooling rates}

In order to verify the nucleation mechanisms of the primary $\alpha$-Al phase in Al-Si12, the microstructures of single particles treated by DFSC at different cooling rates were investigated by SEM. Figure 6 shows the cross-sectional SEM images of single Al-Si12 particles for the two undercooling groups which were solidified at $100 \mathrm{~K} \mathrm{~s}^{-1}, 500 \mathrm{~K} \mathrm{~s}^{-1}, 5000 \mathrm{~K} \mathrm{~s}^{-1}$ and $50,000 \mathrm{~K} \mathrm{~s}^{-1}$, respectively. Although DFSC data could not be evaluated properly for large particles and high cooling rates (e.g. $31 \mu \mathrm{m}$ at $50,000 \mathrm{~K} \mathrm{~s}^{-1}$ ) due to thermal lag, particle microstructures from rapid solidification experiments at high cooling rates still provide useful information understanding the rapid solidification behaviour of Al-Si12 powder particles. The particle diameters and associated undercooling from DFSC are shown in Fig. 6 for Group I (left part, from top to bottom): $20 \mu \mathrm{m}$ and $89 \mathrm{~K}, 22 \mu \mathrm{m}$ and $113 \mathrm{~K}, 19 \mu \mathrm{m}$ and $115 \mathrm{~K}, 21 \mu \mathrm{m}$ and $137 \mathrm{~K}$, respectively. For Group II (Fig. 6, right part, from top to bottom), the particle diameters and associated undercooling from DFSC are $33 \mu \mathrm{m}$ and $76 \mathrm{~K}, 34 \mu \mathrm{m}$ and $91 \mathrm{~K}, 32 \mu \mathrm{m}$ and $93 \mathrm{~K}$, and $31 \mu \mathrm{m}$ and $96 \mathrm{~K}$, respectively. In all cases, the microstructure consists of $\alpha$-Al dendrites and $(\alpha-\mathrm{Al}+\mathrm{Si})$ eutectic due to the coupled zone [33, 34], where the grey and bright areas are $\mathrm{Al}$ and $\mathrm{Si}$, respectively. As expected, the microstructure becomes finer with increasing cooling rate. It can be concluded in Fig. 6 (left, Group I) that the $\alpha$-Al dendrites have formed from the particle surface. This result confirms the surface heterogeneous nucleation, which is consistent with the suggested theoretical model based on the DFSC results. For example, for the particle of $19 \mu \mathrm{m}$ in diameter and $115 \mathrm{~K}$ undercooling (left middle in Fig. 6), the microstructure is similar for the case in which nucleation events occur at the surface as illustrated in [13, 48] schematically. During cooling, the particle nucleated from the surface (left side of the particle), leading to finer microstructure of $\alpha-\mathrm{Al}$ in the left side of the particle than that in the right side. As the solidification proceeded further away from the nucleation region, the microstructure of $\alpha$-Al becomes coarser due to the influence of the recalescence effect inside the particle. Similar behaviour can be found for the particle of $22 \mu \mathrm{m}$ and $113 \mathrm{~K}$. For Group II (Fig. 6, right), different microstructural features were observed. With increasing cooling rate, $\alpha-\mathrm{Al}$ dendrites have formed simultaneously at the surface and on inclusions inside the particle. For example, for the particle of $31 \mu \mathrm{m}$ and $96 \mathrm{~K}$ (right bottom in Fig. 6), $\alpha$ $\mathrm{Al}$ dendrites grow from the surface as well as from an inclusion in the particle volume (marked by a red circle). This is consistent with the transition of the nucleation mechanism from surface heterogeneous nucleation to bulk heterogeneous nucleation. 
Figure 6 SEM secondary electron micrographs of single particles solidified at different cooling rates. Particle diameters, cooling rates and undercooling are given. Red circle indicates heterogeneous bulk nucleation on an inclusion.

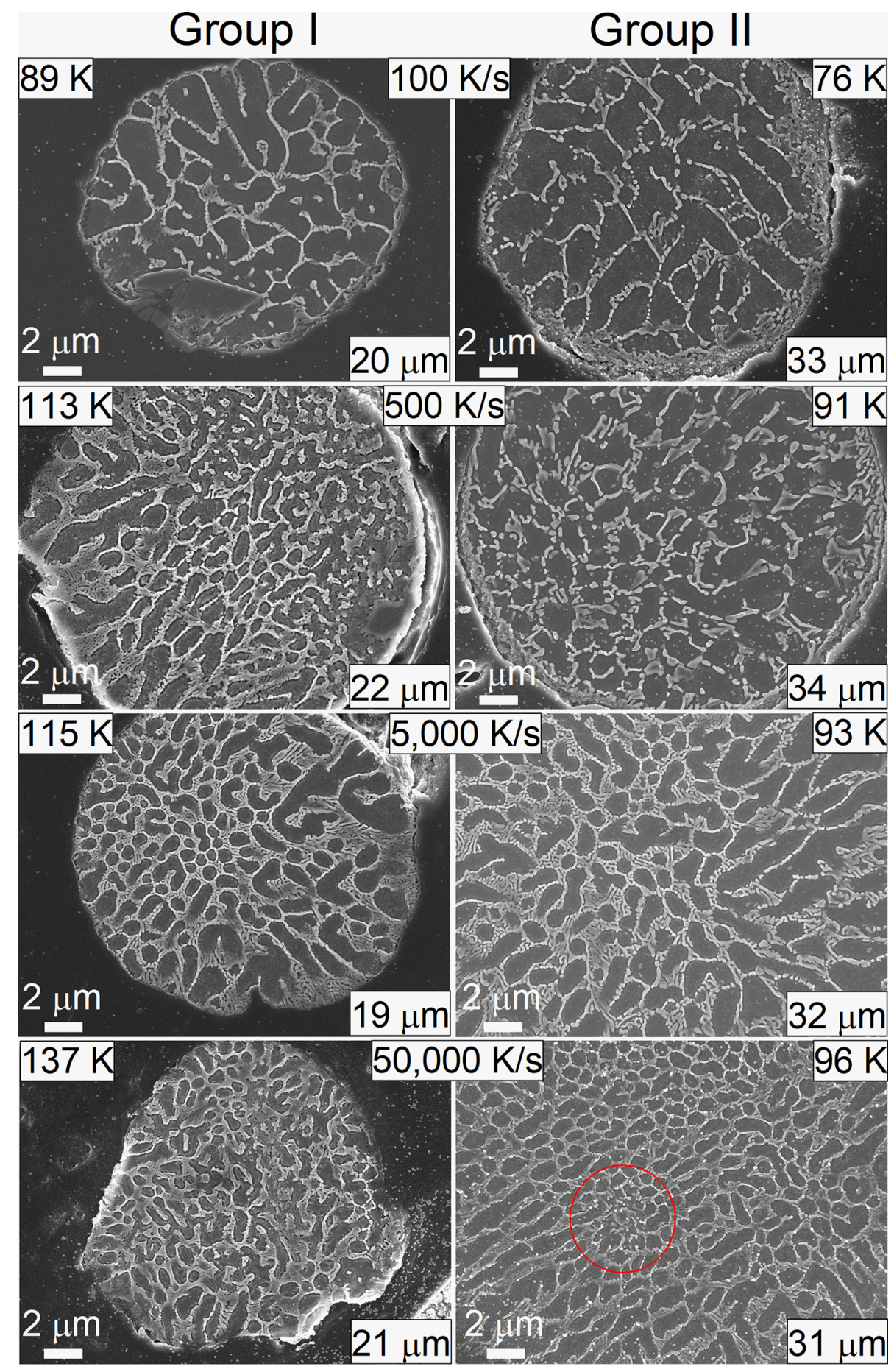

Moreover, the increasing cooling rate contributes to finer $\mathrm{Si}$ in the eutectic, while the $\mathrm{Si}$ morphology seems to change from more fibrous to more globular.

To examine the change of morphologies of the primary $\alpha-\mathrm{Al}$ in more detail, the $\alpha$-Al DAS is plotted in Fig. 7a depending on the cooling rate. Each point corresponds to one particle shown in Fig. 6. The solidification microstructures are dependent on the cooling rate and nucleation undercooling of the primary $\alpha$-Al. When the particle solidifies at high cooling rates with large nucleation undercooling, the nucleation rate of primary $\alpha$-Al increases, and the solidification time is shorter. Thus, the $\alpha$-Al DAS is reduced, and the microstructure is finer, which can 
promote the alloy properties. Moreover, the primary $\alpha$-Al size in the smaller particles (ca. $20 \mu \mathrm{m}$ in diameter, Group I) is smaller than that in the larger particles (ca. $32 \mu \mathrm{m}$ in diameter, Group II) at a particular cooling rate.

In general, the relationship between the dendrite arm spacing and cooling rate can be expressed by $[21,49]$

$\lambda=B \beta_{c}^{-n}$

where $\lambda$ is the dendrite arm spacing in $\mu \mathrm{m}$, and $B$ and $n$ are alloy-dependent fitting parameters. The fitted curves are also plotted in Fig. 7a for the two undercooling groups I and II. $B$ and $n$ of rapidly cooled aluminium alloys via splat quenching were reported to equal 43.2 and 0.324 [49], which is also plotted in
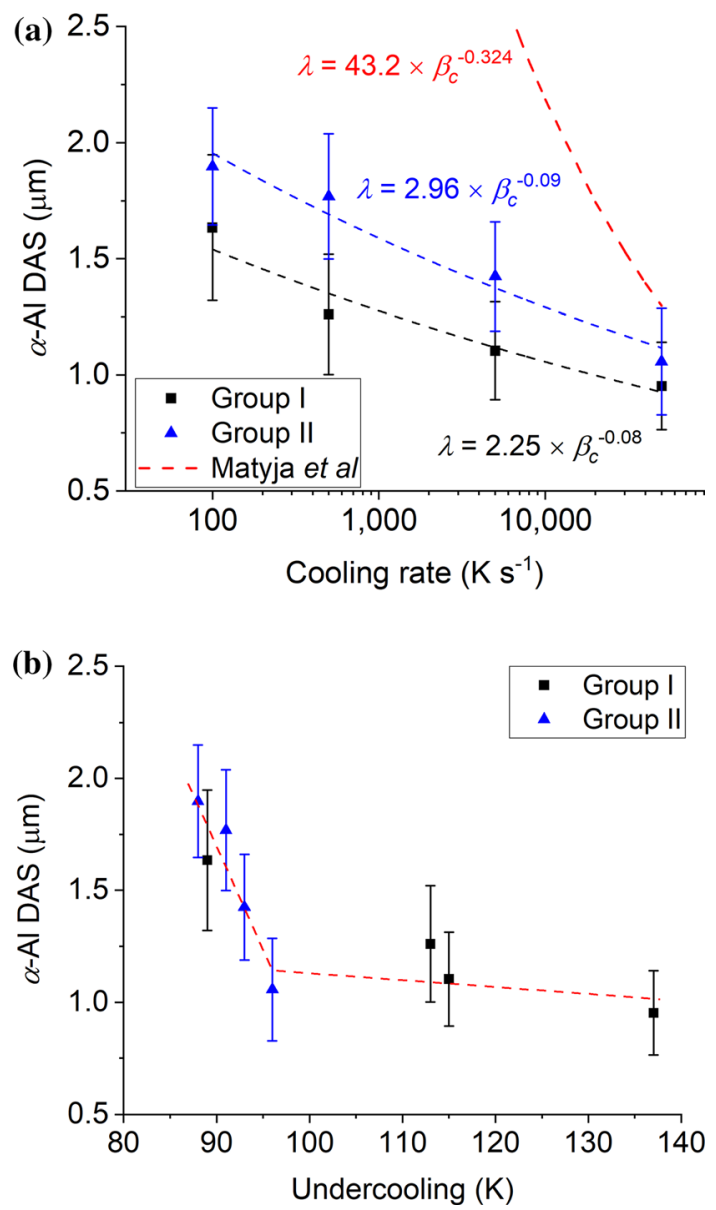

Figure $7 \alpha$-Al dendrite arm spacing as functions of the cooling rate $\mathbf{a}$ and the nucleation undercooling $\mathbf{b}$ for single Al-Si12 particles as shown in Fig. 6. The results from rapidly cooled aluminium alloy by Matyja et al. [49] are also plotted in a. The dashed curves in a show the fitted curves by Eq. (13). The dashed line in $\mathbf{b}$ is a guide for the eye. The error bar shows the standard deviation.
Fig. 7a for comparison. It looks as if the influence of the cooling rate on the DAS is underestimated in the present work, compared to [49]. Such low values of the exponent n (0.08 and 0.09 for Groups I and II, respectively) indicate that the DAS is not only governed by coarsening, but also influenced by the high nucleation undercooling and heat distribution effects in the constrained volume of the particle. In splat quenching as well as AM, the solidified volume is significantly larger than that of individual particles. In this case, bulk nucleation is more relevant than surface nucleation. This is in general agreement with the results in Fig. 7, where the DAS decreases with increasing cooling rate. The results in [49] are close to the Group II results at a high cooling rate of $50,000 \mathrm{~K} \mathrm{~s}^{-1}$. Deviations are attributed to the differences between splat quenching and single particle solidification as described above. To represent AM microstructures, in which bulk heterogeneous nucleation dominates, it is suggested that Group II particles, i.e. particles larger than about $30 \mu \mathrm{m}$, should be used in DFSC. Further, the dependence of the $\alpha$-Al DAS on the nucleation undercooling is shown in Fig. $7 b$. The $\alpha$-Al DAS decreases rapidly in the moderate undercooling range below ca. $95 \mathrm{~K}$, and then decreases slowly at larger undercoolings. This result indicates that the $\alpha$-Al DAS may be related not only to the cooling rate but also to the nucleation undercooling and volume constrictions. In comparison, similar $\alpha$-Al DAS of about $1 \mu \mathrm{m}$ surrounded by $(\alpha-$ $\mathrm{Al}+\mathrm{Si}$ ) eutectics was observed in AM components, e.g. LPBF of AlSi10Mg [50, 51], laser deposited A14047 [52] and LPBF of Al-Si12 [53]. This proves the feasibility of DFSC studies at lager undercoolings (above ca. $95 \mathrm{~K}$ ) and higher cooling rates (above ca. 10,000 $\mathrm{K} \mathrm{s}^{-1}$ ) to represent typical AM microstructures.

\section{Conclusions}

The rapid solidification process of single micro-sized Al-Si12 (mass\%) particles was successfully investigated in a wide range of cooling rates from 100 to $90,000 \mathrm{~K} \mathrm{~s}^{-1}$ by in situ DFSC. With increasing cooling rate, the nucleation undercooling increases for all particles irrespective of their diameter. According to a modified theoretical model based on CNT, the $\alpha$-Al nuclei either form at the surface $\left(\mathrm{Al}_{2} \mathrm{O}_{3}\right.$ layer) or on impurities inside the Al-Si12 particle. For smaller size particles $(<23 \mu \mathrm{m}$ in diameter $)$, surface heterogeneous nucleation dominates in the whole 
investigated cooling rate range. For single Al-Si12 particles with larger size ( $>23 \mu \mathrm{m}$ in diameter), the dominant nucleation mechanism of the primary $\alpha-\mathrm{Al}$ phase changes from surface to bulk heterogeneous nucleation with increasing cooling rate.

Undercooling of rapidly solidified single microsized particles treated by DFSC was correlated with a microstructure investigation. The results reveal that the solidification microstructure consists of fine primary $\alpha$-Al phase and $(\alpha-\mathrm{Al}+\mathrm{Si})$ eutectic. Moreover, the dendrite arm spacing (DAS) is found to noticeably decrease as the cooling rate/undercooling increases. The morphology change of the primary $\alpha$ $\mathrm{Al}$ phase gives some hints on the nucleation mechanism (surface/bulk) change with cooling rate, as described by the theoretical model.

Combining in situ DFSC with microstructure characterisation, it is possible to observe rapidly solidified structures of single metallic particles by controlled rapid cooling and known nucleation undercooling. The results indicate that large nucleation undercoolings above $95 \mathrm{~K}$, high DFSC cooling rates above about $10,000 \mathrm{~K} \mathrm{~s}^{-1}$ and particle diameters above about $30 \mu \mathrm{m}$ should be used to represent AM microstructures successfully. Therefore, this is an effective approach for the investigation of the influence of the cooling rate and undercooling on microstructure evolution under conditions of rapid solidification, such as in AM processes.

\section{Acknowledgements}

BY acknowledges support from the German Research Foundation (Project YA417/4-1). MR acknowledges support from the German Research Foundation (Project RE1261/23-1, SPP 2122). CS acknowledges financial support from the Ministry of Education and Science of the Russian Federation grant 14.Y26.31.0019. OK acknowledges support from the German Research Foundation (Project KE616/29-1 and KE616/27-1, SPP2122). The authors also thank Dr. Bilal Gökce from the University of DuisburgEssen for XRF analysis.

\section{Funding}

Open Access funding enabled and organized by Projekt DEAL.

\section{Declarations}

Conflict of interest The authors declare that they have no conflict of interest.

Open Access This article is licensed under a Creative Commons Attribution 4.0 International License, which permits use, sharing, adaptation, distribution and reproduction in any medium or format, as long as you give appropriate credit to the original author(s) and the source, provide a link to the Creative Commons licence, and indicate if changes were made. The images or other third party material in this article are included in the article's Creative Commons licence, unless indicated otherwise in a credit line to the material. If material is not included in the article's Creative Commons licence and your intended use is not permitted by statutory regulation or exceeds the permitted use, you will need to obtain permission directly from the copyright holder. To view a copy of this licence, visit http://creativecommons.org/licen ses/by $/ 4.0 /$.

\section{Appendix}

\section{Temperature calibration and correction for DFSC measurements}

\section{Primary temperature calibration}

Primary temperature calibration of the whole DFSC instrument (including the thermopile of the sensor, electronics, etc.) was performed prior to the experiments by measuring the phase transition of standard material, in other words to obtain the function of the thermopile voltage reading from the instrument in dependency on the certified temperatures of the standard under given experimental conditions (e.g. heating rate equals zero, certain purge gas, given surrounding temperature, etc.). The temperature of the central area of the sensor is influenced by the surrounding temperature of the sensor housing, which was at room temperature in this study, and the measured thermopile voltage originating from the temperature difference between hot and cold junctions [54]. This voltage has to be calibrated in the temperature range from room temperature up to the 
required maximum temperature, which was $707^{\circ} \mathrm{C}$ in this study. The temperature was therefore calibrated under the same experimental conditions as in the solidification measurements, applying the melting temperatures of indium $\left(156.6^{\circ} \mathrm{C}\right)$, tin $\left(231.9{ }^{\circ} \mathrm{C}\right)$ and zinc $\left(419.5^{\circ} \mathrm{C}\right)$, and the solid-state transition temperature of $\mathrm{K}_{2} \mathrm{SO}_{4}\left(585{ }^{\circ} \mathrm{C}\right)$. It should be pointed out that the thermopile voltage at the phase transition temperature of a calibration material is correlated with a heating rate of $0 \mathrm{~K} \mathrm{~s}^{-1}$. This value was obtained from the measured thermopile voltage of the phase transition at different heating rates, extrapolating to the zero heating rate (e.g. see Fig. 8). Then, the functional relationship between the
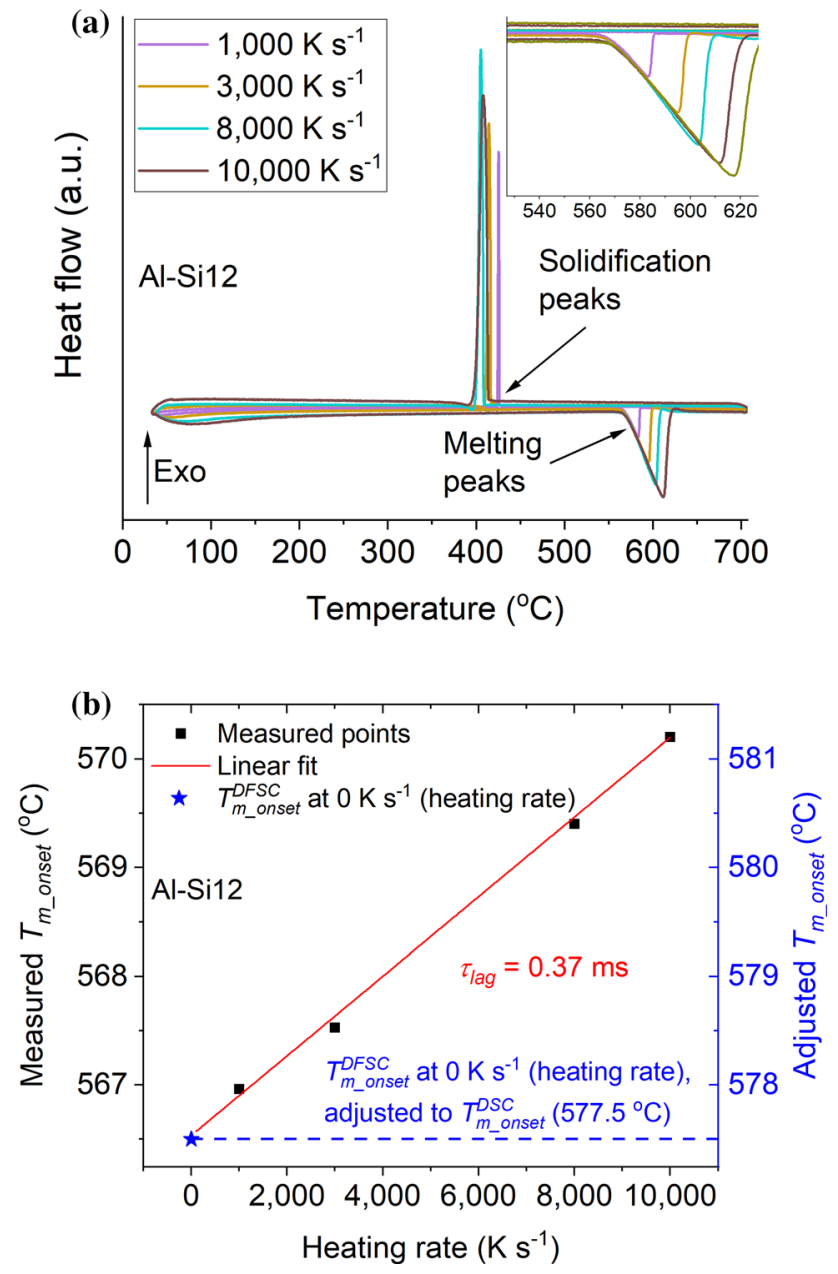

Figure 8 a Heating and cooling curves for different rates of a single Al-Si12 particle (13 $\mu \mathrm{m}$ in diameter). The inset shows the enlarged melting peaks. $\mathbf{b}$ Heating rate dependence of measured apparent melting onset temperatures of a single Al-Si12 particle (13 $\mu \mathrm{m}$ in diameter), extrapolated to $0 \mathrm{~K} \mathrm{~s}^{-1}$. thermopile voltage and temperature was approximated by a quadratic polynomial function [54, 55],

$E=c_{0}+c_{1} T+c_{2} T^{2}$

where $E$ is the thermopile voltage, $T$ is the temperature and $c_{0}, c_{1}$ and $c_{2}$ are fitting parameters determined as $0,6.5 \times 10^{-4}$ and $4.2 \times 10^{-7}$, respectively. With the resulting function, extrapolated to $707^{\circ} \mathrm{C}$, the DFSC instrument was calibrated for the temperature range from room temperature to $707^{\circ} \mathrm{C}$. The sensors used in this study came from the same wafer and were therefore almost identical. Consequently, this calibration function was used for all DFSC measurements.

\section{Temperature correction for each individual Al-Si12 particle}

Apart from primary temperature calibration of the DFSC instrument, the measured temperature should also be corrected for each individual particle. Therefore, before investigating the rapid solidification of each particle by DFSC, the individual particle was heated and cooled at different rates (from 1000 to $10,000 \mathrm{~K} \mathrm{~s}^{-1}$ ) from 37 to $707^{\circ} \mathrm{C}$ and back to $37^{\circ} \mathrm{C}$ under an argon atmosphere at a constant pressure of $100 \mathrm{kPa}$. As an example, the measured curves at different heating-cooling rates from 1000 to $10,000 \mathrm{~K} \mathrm{~s}^{-1}$ for one single Al-Si12 particle are shown in Fig. 8a. As expected, the leading edges of the melting peaks overlap due to the thermal resistance of the sensor/sample system, which limits the heat flow during melting $[28,56]$. The measured temperature at different scanning rates has to be corrected regarding three sources of temperature errors:

(i) The temperature gradient inside the particle due to the limited heat conductivity of the particle. For metallic particles, this temperature gradient is relatively small (a few Kelvins) [46, 57]. Therefore, this error is neglected for the temperature correction in this study.

(ii) The dynamic temperature offset $\left(\Delta T_{d}\right.$, due to thermal lag), which can be expressed as in $[28,58]$ for heating

$\Delta T_{d}=\tau_{\text {lag }} \beta_{\mathrm{h}}$

and for cooling 
$\Delta T_{d}=-\tau_{\operatorname{lag}} \beta_{\mathrm{c}}$

where $\beta_{\mathrm{h}}$ and $\beta_{\mathrm{c}}$ are the heating and cooling rates, and $\tau_{\text {lag }}$ is the thermal lag. The thermal lag is determined by the thermal resistance, i.e. the thermal contact, between the particle and the sensor and the thermal resistance inside the sensor membrane. For Al-Si12 particles in the micron range, no size or rate dependence for the eutectic temperature, i.e. the melting onset temperature, is expected. According to Eq. (15a), the dynamic temperature offset $\left(\Delta T_{d}\right)$ increases linearly with the rate. Consequently, the apparent melting onset temperature measured should also increase linearly with the increasing heating rate. Figure $8 \mathrm{~b}$ shows this dependency for a $13 \mu \mathrm{m}$ diameter particle. The apparent melting onset temperatures are on a straight line, confirming the validity of Eq. (15a) for the case under investigation.

(iii) The static temperature offset due to a balance between the heat provided by the heater and the heat losses from the sample to the surroundings, even under isothermal conditions [56, 59]. For example, for a spherical particle, the larger additional heat-exchanging surface compared to a flat sample causes significantly higher heat losses into the surrounding gas. Besides, the small contact area between the spherical particle and the membrane results in a relatively large thermal resistance between the sample and membrane. In addition, the particle position relative to the sensor heater and the thermopile also has an influence. If the particle is placed away from the heater, say close to the thermopile in the centre, the sample temperature will be lower compared to a situation where the particle is closer to the heater. This offset is independent of the heating or cooling rate and can reach some few tens of Kelvin. Therefore, it is important to place the sample properly and to correct this offset after the measurements. For the Al-Si12 alloy, particles start to melt at the eutectic temperature during heating, i.e. the melting onset temperature equals the eutectic temperature. Therefore, it is assumed that the static temperature offset at this temperature is the offset between the true eutectic temperature of the Al-Si alloy and the measured apparent melting onset temperature at $0 \mathrm{~K} \mathrm{~s}^{-1}$. The eutectic temperature can be found in Ref. [27] $\left(577 \pm 1{ }^{\circ} \mathrm{C}\right)$ or measured by differential scanning calorimetry (DSC) $\left(577.5{ }^{\circ} \mathrm{C}\right.$ for the as-atomised Al-Si12 powders investigated here). The measured melting onset temperature at $0 \mathrm{~K} \mathrm{~s}^{-1}$ can be obtained from the melting onset temperatures measured at different heating rates extrapolating to zero heating rate by Eq. (15a). For the particle shown in Fig. 2, this offset is $-11 \mathrm{~K}$ (see Fig. 8b: axis intercept $566.5-577.5^{\circ} \mathrm{C}$ ). In other words, the extrapolated $\left(\beta_{\mathrm{h}}=0\right)$ measured melting onset temperature for the particle shown in Fig. 2 is lower than the real temperature. A possible reason is that the particle is "thermally" much closer to the heater than to the thermopile, as shown in Fig. 2. Hence, particle placement is essential for accurate absolute temperature measurements for such particles. For simplicity and because of the dominance of heat conduction [57], it is assumed that the static offset is proportional to the temperature difference between room temperature and the measured apparent temperature. Thus, the static offset, $\Delta T_{s}$, is expressed by

$\Delta T_{s}=\left(T_{m_{-} \text {onset }}^{\text {DFSC }}-T_{m_{-} \text {onset }}^{\text {DSC }}\right) \frac{T_{\text {measure }}-T_{R T}}{T_{m_{-} \text {onset }}^{\text {DSC }}-T_{R T}}$

where $T_{m_{-} \text {onset }}^{\mathrm{DFSC}}$ and $T_{m_{-} \text {onset }}^{\mathrm{DSC}}\left(577.5^{\circ} \mathrm{C}\right.$ for asatomised $\mathrm{Al}-\mathrm{Si1} 2$ powders) are the melting onset temperatures at $0 \mathrm{~K} \mathrm{~s}^{-1}$ heating rate measured by DFSC and DSC, $T_{\text {measure }}$ is the measured thermopile (apparent) temperature and $T_{R T}$ is room temperature.

Each individual measured particle was different in size, position on the sensor and thermal contact. Therefore, the measured temperature of each particle must be corrected in a proper manner. Since solidification (nucleation) is a stochastic process, a comparison of the characteristic temperature of solidification obtained during cooling with the respective literature data is impossible. Instead, assuming good symmetry of the DFSC instrument (in terms of thermal behaviour during heating and 
cooling $[28,58])$, the correction function (Eq. 15a) on heating can be utilised on cooling as well (Eq. 15b). Thus, the measured apparent onset temperatures during heating and cooling can be evaluated with respect to a correction function:

for heating

$$
\begin{aligned}
T_{\text {correct }}= & T_{\text {measure }}-\tau_{\text {lag }} \beta_{\mathrm{h}} \\
& -\left(T_{m \_ \text {onset }}^{\text {DFSC }}-T_{m \_ \text {onset }}^{\text {DSC }}\right) \frac{T_{\text {measure }}-T_{R T}}{T_{m \_ \text {onset }}^{\text {DSC }}-T_{R T}}
\end{aligned}
$$

and for cooling

$$
\begin{aligned}
T_{\text {correct }}= & T_{\text {measure }}+\tau_{\text {lag }} \beta_{\mathrm{c}} \\
& -\left(T_{m \_ \text {onset }}^{\text {DFSC }}-T_{m \_ \text {onset }}^{\text {DSC }}\right) \frac{T_{\text {measure }}-T_{R T}}{T_{m \_ \text {onset }}^{\text {DSC }}-T_{R T}}
\end{aligned}
$$

where $T_{\text {correct }}$ is the corrected temperature. The measured apparent melting and solidification onset temperatures were therefore corrected by Eqs. (17a and $17 \mathrm{~b})$.

\section{References}

[1] Sercombe TB, Schaffer GB (2003) Rapid manufacturing of aluminum components. Science 301(5637):1225-1227. http s://doi.org/10.1126/science.1086989

[2] Buchbinder D, Meiners W, Wissenbach K, Poprawe R, Kaierle S (2015) Selective laser melting of aluminum diecast alloy - correlations between process parameters, solidification conditions, and resulting mechanical properties. J Laser Appl 27(S2):S29205. https://doi.org/10.2351/1. 4906389

[3] Konrad C, Zhang Y, Xiao B (2005) Analysis of melting and resolidification in a two-component metal powder bed subjected to temporal gaussian heat flux. Int J Heat Mass Transf 48(19-20):3932-3944. https://doi.org/10.1016/j.ijheatmasstr ansfer.2005.04.010

[4] Konrad C, Zhang Y, Shi Y (2007) Melting and resolidification of a subcooled metal powder particle subjected to nanosecond laser heating. Int $J$ Heat Mass Transf 50(11-12):2236-2245. https://doi.org/10.1016/j.ijheatmasstr ansfer.2006.10.041

[5] Gusarov AV, Yadroitsev I, Bertrand P, Smurov I (2007) Heat transfer modelling and stability analysis of selective laser melting. Appl Surf Sci 254(4):975-979. https://doi.org/10. 1016/j.apsusc.2007.08.074

[6] Gu DD, Meiners W, Wissenbach K, Poprawe R (2012) Laser additive manufacturing of metallic components: materials, processes and mechanisms. Int Mater Rev 57(3):133-164. h ttps://doi.org/10.1179/1743280411Y.0000000014

[7] Li Y, Gu D (2014) Parametric analysis of thermal behavior during selective laser melting additive manufacturing of aluminum alloy powder. Mater Des 63:856-867. https://doi. org/10.1016/j.matdes.2014.07.006

[8] Doubenskaia MA, Zhirnov IV, Teleshevskiy VI, Bertrand P, Smurov IY (2015) Determination of true temperature in selective laser melting of metal powder using infrared camera. Mater Sci Forum 834:93-102

[9] Li XP, Wang XJ, Saunders M, Suvorova A, Zhang LC, Liu YJ, Fang MH, Huang ZH, Sercombe TB (2015) A selective laser melting and solution heat treatment refined $\mathrm{Al}-12 \mathrm{Si}$ alloy with a controllable ultrafine eutectic microstructure and 25\% tensile ductility. Acta Mater. https://doi.org/10.1016/j.ac tamat.2015.05.017

[10] Farshidianfar MH, Khajepour A, Gerlich AP (2016) Effect of real-time cooling rate on microstructure in laser additive manufacturing. J Mater Process Technol 231:468-478. http s://doi.org/10.1016/j.jmatprotec.2016.01.017

[11] Hooper PA (2018) Melt pool temperature and cooling rates in laser powder bed fusion. Addit Manuf 22:548-559. http s://doi.org/10.1016/j.addma.2018.05.032

[12] Bendijk A, Delhez R, Katgerman L, de Keijser TH, Mittemeijer EJ, Van Der Pers NM (1980) Characterization of AlSi-alloys rapidly quenched from the melt. J Mater Sci 15(11):2803-2810. https://doi.org/10.1007/BF00550549

[13] Trivedi R, Jin F, Anderson IE (2003) Dynamical evolution of microstructure in finely atomized droplets of Al-Si alloys. Acta Mater 51(2):289-300. https://doi.org/10.1016/S1359-6 454(02)00226-4

[14] Srivastava VC, Mandal RK, Ojha SN (2004) Evolution of microstructure in spray formed $\mathrm{Al}-18 \% \mathrm{Si}$ alloy. Mater Sci Eng A 383(1):14-20. https://doi.org/10.1016/j.msea.2004.0 2.031

[15] Roehling JD, Coughlin DR, Gibbs JW, Baldwin JK, Mertens JCE, Campbell GH, Clarke AJ, McKeown JT (2017) Rapid solidification growth mode transitions in Al-Si alloys by dynamic transmission electron microscopy. Acta Mater 131:22-30. https://doi.org/10.1016/j.actamat.2017.03.061

[16] Das SK, Perepezko JH, Wu RI, Wilde G (2001) Undercooling and glass formation in Al-based alloys. Mater Sci Eng A 304-306:159-165

[17] Perepezko JH, Sebright JL, Höckel PG, Wilde G (2002) Undercooling and solidification of atomized liquid droplets. Mater Sci Eng A 326(1):144-153

[18] Perepezko JH, LeBeau SE, Mueller BA, Hildeman GJ (1986). In: Fine ME, Starke EA (eds) Rapidly solidified powder aluminum alloys. PA, ASTM International, West Conshohocken, pp 118-136 
[19] Liebermann HH (1993) Rapidly solidified alloys: processes, structures, properties, applications. Marcel Dekker, INC., New York

[20] Grant PS, Cantor B, Katgerman L (1993) Modelling of droplet dynamic and thermal histories during spray forming - I. Individual droplet behaviour. Acta Metall et Mater 41(11):3097-3108. https://doi.org/10.1016/0956-7151(93)9 0039-U

[21] Lavernia EJ, Ayers JD, Srivatsan TS (1992) Rapid solidification processing with specific application to aluminium alloys. Int Mater Rev 37(1):1-44. https://doi.org/10.1179/i mr.1992.37.1.1

[22] Kurz W, Giovanola B, Trivedi R (1986) Theory of microstructural development during rapid solidification. Acta Metall 34(5):823-830. https://doi.org/10.1016/0001-6 160(86)90056-8

[23] Zhuravlev E, Schick C (2010) Fast scanning power compensated differential scanning nano-calorimeter: 1 the device. Thermochim Acta 50(1-2):1-13

[24] Yang B, Abyzov AS, Zhuravlev E, Gao Y, Schmelzer JWP, Schick C (2013) Size and rate dependence of crystal nucleation in single tin drops by fast scanning calorimetry. J Chem Phys 138(5):54501

[25] Guan W, Gao Y, Zhai Q, Xu K (2004) Effect of droplet size on nucleation undercooling of molten metals. J Mater Sci 39(14):4633-4635

[26] Weck E, Leistner E (1986) Metallographic instructions for colour etching by immersion, part iii: non-ferrous metals, cemented carbides and ferrous metals, nickel-base and cobaltbase alloys. Deutscher Verlag für Schweißtechnik, Düsseldorf

[27] Baker H, Okamoto H (1992) ASM Handbook: Alloy Phase Diagrams. ASM Handbook 3. ASM International, Materials Park, Ohio

[28] Höhne G, Cammenga HK, Eysel W, Gmelin E, Hemminger W (1990) The temperature calibration of scanning calorimeters. Thermochim Acta 160(1):1-12. https://doi.org/ 10.1016/0040-6031(90)80235-Q

[29] Milkereit B, Meißner Y, Ladewig C, Osten J, Yang B, Springer A, Keßler O (2021) Metallographic preparation of single powder particles. Pract Metallogr 58(3):129-139. h ttps://doi.org/10.1515/pm-2021-0009

[30] Gündüz M, Çadırlı E (2002) Directional solidification of aluminium-copper alloys. Mater Sci Eng A 327(2):167-185. https://doi.org/10.1016/S0921-5093(01)01649-5

[31] Wilde G, Sebright JL, Perepezko JH (2006) Bulk liquid undercooling and nucleation in gold. Acta Mater 54(18):4759-4769

[32] Gandin C-A, Mosbah S, Volkmann T, Herlach DM (2008) Experimental and numerical modeling of equiaxed solidification in metallic alloys. Acta Mater 56(13):3023-3035
[33] Pierantoni M, Gremaud M, Magnin P, Stoll D, Kurz W (1992) The coupled zone of rapidly solidified Al-Si alloys in laser treatment. Acta Metall et Mater 40(7):1637-1644. h ttps://doi.org/10.1016/0956-7151(92)90106-o

[34] Kurz W, Fisher DJ (1979) Dendrite growth in eutectic alloys: the coupled zone. Int Met Rev 24(1):177-204

[35] Turnbull D (1950) Formation of crystal nuclei in liquid metals. J Appl Phys 21(10):1022-1028

[36] Gutzow I, Schmelzer JWP (1995) The vitreous state: thermodynamics, structure, rheology, and crystallization. Springer-Verlag, Berlin

[37] Thompson CV, Spaepen F (1979) On the approximation of the free energy change on crystallization. Acta Metall 27(12):1855-1859. https://doi.org/10.1016/0001-6160(79)9 $0076-2$

[38] Iwamatsu M (2015) Line-tension effects on heterogeneous nucleation on a spherical substrate and in a spherical cavity. Langmuir 31(13):3861-3868. https://doi.org/10.1021/la $504926 \mathrm{~s}$

[39] Gremaud M, Allen DR, Rappaz M, Perepezko JH (1996) The development of nucleation controlled microstructures during laser treatment of $\mathrm{Al}-\mathrm{Si}$ alloys. Acta Mater 44(7):2669-2681

[40] Korb LJ, Olson DL (1992) ASM Handbook: Corrosion. ASM Handbook 13. ASM International, Materials Park, Ohio

[41] Gündüz M, Hunt JD (1985) The measurement of solid-liquid surface energies in the Al-Cu Al-Si and Pb-Sn systems. Acta Metall 33(9):1651-1672. https://doi.org/10.1016/0001-6160 (85)90161-0

[42] Kalay YE, Chumbley LS, Anderson IE, Napolitano RE (2007) Characterization of hypereutectic Al-Si powders solidified under far-from equilibrium conditions. Metall Mater Trans A 38(7):1452-1457. https://doi.org/10.1007/s1 1661-007-9168-8

[43] Uttormark MJ, Zanter JW, Perepezko JH (1997) Repeated nucleation in an undercooled aluminum droplet. J Cryst Growth 177(3-4):258-264

[44] Cantor B (2003) Heterogeneous nucleation and adsorption. Philos Trans R Soc A 361:409-417

[45] Ksiazek M, Sobczak N, Mikulowski B, Radziwill W, Surowiak I (2002) Wetting and bonding strength in $\mathrm{Al} / \mathrm{Al} 2 \mathrm{O} 3$ system. Mater Sci Eng A 324(1-2):162-167. https://doi.org/ 10.1016/S0921-5093(01)01305-3

[46] Yang B, Gao Y, Zou C, Zhai Q, Abyzov AS, Zhuravlev E, Schmelzer JWP, Schick C (2011) Cooling rate dependence of undercooling of pure $\mathrm{Sn}$ single drop by fast scanning calorimetry. Appl Phys A 104(1):189-196. https://doi.org/ $10.1007 / \mathrm{s} 00339-010-6100-7$ 
[47] Perepezko JH (1997) Kinetic processes in undercooled melts. Mater Sci Eng A 226-228:374-382

[48] Boettinger WJ, Coriell SR (1986). In: Sahm PR, Jones H, Adam CM (eds) Science and technology of the undercooled melt: rapid solidification materials and technologies. Springer, Netherlands, Dordrecht, pp 81-109

[49] Matyja H, Giessen BC, Grant NJ (1968) Effect of cooling rate on dendrite spacing in splat-cooled aluminium alloys. J Inst Metals 96:30-32

[50] Delahaye J, Tchuindjang JT, Lecomte-Beckers J, Rigo O, Habraken AM, Mertens A (2019) Influence of Si precipitates on fracture mechanisms of AlSi10Mg parts processed by selective laser melting. Acta Mater 175:160-170. https://oi. org/10.1016/j.actamat.2019.06.013

[51] Kleiner S, Zürcher J, Bauer O, Margraf P (2020) Heat treatment response of selectively laser melted AlSi10Mg. HTM 75(5):327-341. https://doi.org/10.3139/105.110418

[52] Dinda GP, Dasgupta AK, Mazumder J (2012) Evolution of microstructure in laser deposited Al-11.28\%Si alloy. Surf Coat Technol 206(8-9):2152-2160. https://doi.org/10.1016/ j.surfcoat.2011.09.051

[53] Prashanth KG, Scudino S, Klauss HJ, Surreddi KB, Löber L, Wang Z, Chaubey AK, Kühn U, Eckert J (2014) Microstructure and mechanical properties of Al-12Si produced by selective laser melting: effect of heat treatment. Mater Sci Eng A 590:153-160. https://doi.org/10.1016/j.ms ea.2013.10.023
[54] Schick C, Mathot V (eds) (2016) Fast scanning calorimetry. Springer, Berlin

[55] Burns GW, Scroger MG, Strouse GF, Croarkin MC, Guthrie WF (1993) NIST monograph 175: temperature-electromotive force reference functions and tables for the letter-designated thermocouple types based on the ITS-90. US GPO, Washington, D.C

[56] Gao YL, Zhuravlev E, Zou CD, Yang B, Zhai QJ, Schick C (2009) Calorimetric measurements of undercooling in single micron sized $\mathrm{SnAgCu}$ particles in a wide range of cooling rates. Thermochim Acta 482(1-2):1-7

[57] Minakov AA, Schick C (2007) Ultrafast thermal processing and nanocalorimetry at heating and cooling rates up to 1 MK/s. Rev Sci Instrum 78(7):73902

[58] Deutsches Institut für Normung e.V. (DIN) (2011) Recommendation for temperature calibration of fast scanning calorimeters (FSCs) for sample mass and scan rate (DIN SPEC 91127). Retrieved from https://www.din.de/en/wdc-be uth:din21:140983524

[59] Simon C, Peterlechner M, Wilde G (2015) Experimental determination of the nucleation rates of undercooled micronsized liquid droplets based on fast chip calorimetry. Thermochim Acta 603:39-45. https://doi.org/10.1016/j.tca.2014. 10.027

Publisher's Note Springer Nature remains neutral with regard to jurisdictional claims in published maps and institutional affiliations. 